\title{
Surfactant composition reflects lung overinflation and arterial oxygenation in patients with acute lung injury
}

\author{
A.D. Bersten*, I.R. Doyle**, K.G. Davidson**, H.A. Barr**, T.E. Nicholas**, F. Kermeen*
}

Surfactant composition reflects lung overinflation and arterial oxygenation in patients with acute lung injury. A.D. Bersten, I.R. Doyle, K.G. Davidson, H.A. Barr, T.E. Nicholas, F. Kermeen. CERS Journals Ltd 1998.

ABSTRACT: Pulmonary surfactant abnormalities have consistently been documented in patients with acute lung injury (ALI), however, there is little evidence directly correlating them to altered respiratory mechanics. To explore this further, surfactant composition was measured in lung aspirate fluid collected on 15 occasions from 10 patients with ALI. The composition was compared with lung aspirate fluid from 11 intubated patients prior to elective cardiac surgery (CS), and bronchoalveolar lavage fluid from 16 normal subjects.

In both the ALI and cardiac groups the proportion of disaturated phospholipids (DSP) and phosphatidylcholine was reduced. Plasma levels of surfactant proteins-A and -B (SP-A and -B) were elevated, but were unrelated to alveolar surfactant levels. In the ALI group, and the ALI + CS group, DSP, normalized to the total phospholipid content, sphingomyelin (SPH), and urea, showed strong direct correlations with arterial oxygen tension/inspiratory oxygen fraction (all pð0.01). In the ALI group, normalized DSP was also directly related to the elastance of the positive end-expiratory pressure-induced increase in the end-expiratory lung volume (all pð0.02), and indirect correlations were found with a measure of lung overinflation $\left(\% E_{2} ;\right.$ all pð0.01).

We conclude that surfactant composition correlates with lung function abnormalities in acute lung injury and cardiac patients, and that both groups had elevated plasma surfactant proteins-A and -B levels, consistent with a concurrent increase in alveolocapillary permeability.

Eur Respir J 1998; 12: 301-308.

The gas-liquid interface of the lung is lined with a complex mixture of phospholipids, neutral lipids, and specific proteins, collectively known as pulmonary surfactant. Surfactant lowers surface tension in a manner directly related to the radius of curvature of the alveoli. In doing so, it reduces the work of breathing and stabilizes the lung, allowing alveoli of different sizes to coexist.

The hallmark of the acute respiratory distress syndrome (ARDS) is an increase in alveolocapillary permeability, atelectasis, and a concomitant deterioration in lung compliance and gas exchange. In 1967, AsнBaugh et al. [1] first showed that surfactant from ARDS patients had an increased minimum surface tension. Since then, it has been established that ARDS surfactant exhibits an increased maximum surface tension [2], and a decreased surface tension hysteresis [3].

Surfactant from patients with acute lung injury (ALI; patients with ARDS as well as those at risk) is deficient in total phospholipid (PL), and contains proportionately less phosphatidylcholine (PC) and phosphatidylglycerol (PG) [2-7]. PIson et al. [3] found that in ALI patients the surfactant PC/PL ratio correlated with surface tension hysteresis and was inversely related to a respiratory failure score. Similarly, GreGory et al. [2] noted that changes in surfactant composition reflected disease severity. However, no study has specifically compared surfactant composition with parameters of lung function and respiratory
*Dept of Critical Care Medicine, and **Dept of Human Physiology, School of Medicine, Flinders University, Adelaide, South Australia.

Correspondence: A.D. Bersten

Dept of Clinical Care Medicine

Flinders Medical Centre

Adelaide, South Australia

Australia, 5042

Fax: 61882045751

Keywords: Acute lung injury acute respiratory distress syndrome

lung function

respiratory mechanics

surfactant phospholipids

surfactant proteins-A and -B

Received: January 311997

Accepted after revision April 71998

This research was supported by the $\mathrm{NH}$ and MRC of Australia, and The Australian Adult Respiratory Distress Syndrome Association. mechanics. If surface tension comprises $2 / 3$ of lung elastance [8], the inverse of compliance, it seems likely that changes in respiratory mechanics in ALI patients will reflect surfactant abnormalities.

To gain further insight into the significance of surfactant status in patients with ALI, we have examined surfactant composition in lung aspirate fluid (LAF) and related it to blood oxygenation and respiratory mechanics. We have also compared ALI composition with that in normal bronchoalveolar lavage (BAL) fluid and LAF from patients undergoing elective cardiac surgery (CS). Finally, ALI is also associated with reduced levels of surfactant protein-A (SP-A) [2, 7], and surfactant protein-B (SP-B) [2]. However, paradoxically, we have recently reported that circulating levels of SP-A and SP-B are increased in ARDS and hydrostatic pulmonary oedema (HPE), in a manner inver-sely related to both blood oxygenation and static respiratory system compliance $[9,10]$. In order to investigate this quandary we have also compared SP-A and -B levels in plasma and LAF fluid.

\section{Methods}

This study was approved by the Committee for Clinical Investigation, Flinders Medical Centre (Permit Nos. 26/ 93, 166/95, and 83/93). Informed consent was obtained from the subjects or their closest relative. 


\section{Sample collection}

Acute lung injury patients. Arterial blood and LAF were obtained from 10 patients with ALI at 07:00 h (table 1). Their ventilator settings had been unchanged for a minimum of $4 \mathrm{~h}$ prior to sampling. Studies were conducted twice on patient 8 , and three times on patients 9 and 10 . Plasma was prepared immediately after collection. Specimens of LAF were collected in disposable aspirating tubes (Luki, 8643-04, Davis and Geck, Wayne, NJ, USA) using a sterile suction catheter gently passed until a sustained resistance was obtained. Patients were manually hyperinflated $(\sim 1500 \mathrm{~mL})$ with $6-8$ breaths of $100 \% \mathrm{O}_{2}$ during this procedure. Samples were stored at $-20^{\circ} \mathrm{C}$ for batch analysis.

Cardiac surgery patients. Additional LAF with concomitant blood for oxygenation and plasma was obtained from 11 patients immediately following intubation and ventilation prior to CS. Matching respiratory mechanics data were not available in these patients.

Normal subjects. BAL fluid was obtained from 16 healthy volunteers. Briefly, a flexible fibreoptic bronchoscope was introduced transnasally with the subject supine. The tip of the bronchoscope was wedged in a right middle lobe segmental bronchus and $4 \times 20 \mathrm{~mL}$ volumes of saline at $37^{\circ} \mathrm{C}$ instilled and withdrawn sequentially, as previously described [11].

\section{Mechanical ventilation and respiratory mechanics in ALI patients}

All ALI patients were sedated with infused morphine and midazolam, and paralysed with pancuronium bromide for the respiratory mechanics measurements. Patients were ventilated using a Puritan-Bennett 7200ae ventilator (Puritan-Bennett Corp., Carlsbad, CA, USA) with a tidal volume $(V \mathrm{~T})$ of $8-10 \mathrm{~mL} \cdot \mathrm{kg}^{-1}$, a square wave inspiratory flow ( $\left.V^{\prime} \mathrm{I}\right)$ pattern, and an inspiratory:expiratory ratio exceeding 1:1. Flow was measured with a heated, Fleischtype pneumotachograph (HP-47034A; Hewlett-Packard, Palo Alto, CA, USA) and transducer (21072A, HewlettPackard), which had been calibrated over the range 0-300 L. min $^{-1}$ with a flow calibration set (18987-1, Gould Godard VB, Bilthoven, The Netherlands). The pneumotachograph was connected between the y-piece of the ventilator tubing and the endotracheal tube. Airway pressure $(P$ aw $)$ was measured proximal to the endotracheal tube by a precalibrated (water manometer) strain gauge transducer (Bell and Howell 4-327-I, Trans-America Delaval, Pasadena, CA, USA). Flow and $P$ aw were recorded on a personal computer via a 12-bit analogue-to-digital converter (DT2801, Data Translation Inc, Marlboro, MA, USA) at $100 \mathrm{~Hz}$ for later data analysis (ANADAT 5.1, RHT-InfoDAT Inc, Montreal, Canada).

Following blood sampling, collection of LAF and 30 min of stable mechanical ventilation, dynamic volumepressure data were collected for $60 \mathrm{~s}$. In turn, this was followed by a prolonged expiration to the relaxation volume of the respiratory system $\left(0 \mathrm{cmH}_{2} \mathrm{O}\right.$ positive end-expiratory pressure (PEEP)). From the quotient of the expired volume and the applied PEEP we calculated the static ela- stance of the PEEP-induced increase in the end-expiratory lung volume $(E \Delta \mathrm{EELV})$. The dynamic respiratory system elastance $(E$ rs,dyn), and a measure of lung overinflation $\left(\% E_{2}\right)$ were calculated from the volume-pressure data as described by Kavo et al. [12]. Briefly, the dynamic volume-pressure data were fitted to a volume-dependent model of elastance where: $P$ aw $=\left(E_{1}+E_{2} V\right) V+R$ rs $V^{\prime}$ I+EEP, where $E_{1}$ is the volume-independent component of dynamic elastance, $E_{2} V$ is the volume-dependent component, $V$ is volume, $R \mathrm{rs}$ is the respiratory system resistance, EEP is the end-expiratory pressure, and $\% E_{2}=\left(100 E_{2} V \mathrm{~T}\right) /\left(E_{1}+\right.$ $\left.E_{2} V \mathrm{~T}\right)$. A $\% E_{2}>30 \%$ indicates lung overinflation [12].

\section{Surfactant analysis}

Surfactant analysis was performed in a blind randomized manner. Phospholipids were extracted from LAF by the method of Bligh and Dyer [11]. Disaturated phospholipids (DSP) were separated by the method of Mason and associates, and the phospholipid content determined by measuring inorganic phosphorus by the Bartlett method [11]. The phospholipid classes were separated by highperformance liquid chromotography (HPLC) as described by PIson et al. [13]. The HPLC system consisted of two pumps (model M-45, Waters Millipore, MA, USA), an LKB autosampler (model 2157, Pharmacia, Uppsala, Sweden) and mass detector (model 750/14, Applied Chromatography System, Cheshire, UK) coupled to a Delta Chromotography Data System programme (Digital Solutions, Margate, Australia) for gradient formation and peak integration. The solvent system consisted of acetonitrilewater (70:30; pH 6.0) (solvent A) and pure acetonitrile (solvent B). A linear gradient from $87 \%$ solvent B to $25 \%$ solvent B was formed between 5 and 25 min with a flow rate of $2 \mu \mathrm{mL} \cdot \mathrm{min}^{-1}$ at room temperature. Either $20 \mu \mathrm{L}$ of lipid extract or phospholipid standard solution was injected onto the column ( $\mu$ Porasil, Waters), then quantified using the mass detector $\left(70^{\circ} \mathrm{C}\right)$. Sphingosine (Sigma, St Louis, MO, USA) was routinely included as an internal standard. The data were normalized using PL, sphingomyelin (SPH), and urea. Surfactant protein-A and -B were measured using enzyme-linked immunosorbent inhibition assays (ELISA), after first delipidating the samples using a Tris buffer containing ethylenediamine tetraacetic acid, sodium dodecyl sulphate and Triton X-100 [9, 10].

\section{Statistics}

The association between variables was performed with Spearman's Rank order correlations since we have no reason to assume a linear relationship holds between the measured variables. Indeed, we have shown that plasma SP-A and -B are not normally distributed [10]. Analysis of variance was used to determine if there were intergroup differences. For simplicity, values are expressed as mean \pm SEM. Significance was accepted at the $5 \%$ level.

\section{Results}

\section{Acute lung injury patients}

Physiological variables. The severity of illness of the ALI patients is reflected in their physiological data, which included an arterial oxygen tension $\left(\mathrm{Pa}_{\mathrm{a}} \mathrm{O}_{2}\right)$ /inspiratory 
Table 1. - Characteristics of study patients

\begin{tabular}{|c|c|c|c|c|c|c|}
\hline No. & Day of MV & Cause of ARF & $P \mathrm{a}, \mathrm{O}_{2} / F \mathrm{I}, \mathrm{O}_{2}$ & $\begin{array}{c}E_{\mathrm{rs}, \mathrm{dyn}} \\
\mathrm{cmH}_{2} \mathrm{O} \cdot \mathrm{L}^{-1}\end{array}$ & $\% E_{2}$ & $\begin{array}{c}E \Delta E E L V \\
\mathrm{cmH}_{2} \mathrm{O} \cdot \mathrm{L}^{-1}\end{array}$ \\
\hline 1 & 3 & Ruptured AAA & 246 & 24.3 & 3.7 & 22.2 \\
\hline 2 & 3 & Multiple trauma & 228 & 28.7 & 38.5 & 13.2 \\
\hline 3 & 1 & Legionnaire's disease & 66 & 25.4 & 49.6 & 13.5 \\
\hline 4 & 3 & Pancreatitis & 245 & 21.9 & -2.2 & 22.5 \\
\hline 5 & 4 & Pulmonary embolus & 145 & 16.1 & 16.6 & 13.6 \\
\hline 6 & 2 & Aspiration & 129 & 24.4 & 27.7 & 13.5 \\
\hline 7 & 7 & Aspiration & 102 & 23.5 & 46.5 & 13.0 \\
\hline \multirow[t]{2}{*}{8} & 1 & Pneumonia & 140 & 28.0 & 24.3 & 15.6 \\
\hline & 3 & & 116 & 36.5 & 40.9 & 17.2 \\
\hline \multirow[t]{3}{*}{9} & 1 & Aspiration & 82 & 15.6 & 40.5 & 9.0 \\
\hline & 2 & & 112 & 21.2 & 50.5 & 7.7 \\
\hline & 7 & & 121 & 12.0 & 31.2 & 6.9 \\
\hline \multirow[t]{3}{*}{10} & 1 & Liver transplant & 157 & 16.1 & 12.1 & 19.2 \\
\hline & 3 & & 180 & 17.1 & 31.0 & 15.7 \\
\hline & 5 & & 162 & 20.2 & 32.4 & 13.8 \\
\hline
\end{tabular}

MV: mechanical ventilation; ARF: acute respiratory failure; $P_{\mathrm{a}, \mathrm{O}_{2}} / F_{\mathrm{I}, \mathrm{O}_{2}}$ : arterial oxygen tension/inspiratory oxygen fraction; $E$ rs,dyn: dynamic respiratory elastance; $\% E_{2}$ : measure of lung inflation derived from dynamic volume/pres-

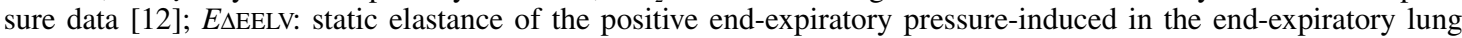
volume; AAA: abdominal aortic aneurysm.

oxygen fraction $\left(F \mathrm{I}, \mathrm{O}_{2}\right)$ of $149 \pm 14 \mathrm{mmHg}$ while ventilated with $7.8 \pm 0.5 \mathrm{cmH}_{2} \mathrm{O}$ PEEP, a $E$ rs,dyn of $22.0 \pm 1.6$ $\mathrm{cmH}_{2} \mathrm{O} \cdot \mathrm{L}^{-1}$ and a lung inflation ratio $\left(\% E_{2}\right)$ of $29.6 \pm 4.2 \%$ (table 1).

Surfactant phospholipid composition. The total phospholipid concentrations $\left(\mu \mathrm{g} \cdot \mu \mathrm{L}^{-1}\right)$ were $148 \pm 16.9$ for ALI LAF, $33.5 \pm 12.0$ for CS LAF, and $36.3 \pm 2.1$ for BAL fluid. The major phospholipid in normal surfactant was PC, comprising $\sim 68 \%$ of PL with $\sim 49 \%$ DSP; however there was relatively less PC and DSP in ALI surfactant (table 2). ALI phospholipid contained proportionally less phosphatidylethanolamine (PE) and phosphatidylinositol (PI) and relatively more SPH (table 2).

Correlation of surfactant with lung function. Irrespective of whether DSP was normalized to PL, SPH, urea [14] or LPC, DSP/PL, DSP/SPH, DSP/urea, and DSP/PLC were directly related to $\mathrm{Pa}, \mathrm{O}_{2} / F \mathrm{I}, \mathrm{O}_{2}$ and $E \Delta \mathrm{EELV}$, and indirectly with $\% E_{2}$. Generally weaker relationships were found for the other phospholipid components, however, no relationship with Ers,dyn was observed. The SP-A/SPH and SP-B/ $\mathrm{SPH}$ ratios were directly related to $\mathrm{Pa}, \mathrm{O}_{2} / \mathrm{FI}_{1} \mathrm{O}_{2}$; and $\mathrm{SP}-\mathrm{A} /$ SPH was inversely related to $\% E_{2}$ (table 3 , and figs. 1 and 2).

\section{Cardiac surgery patients}

The surfactant composition of CS LAF was similar to ALI LAF (table 2), but contained relatively more phosphatidylserine (PS) and lysophosphatidylcholine (LPC). When the CS and ALI data were combined, direct relationships with $\mathrm{Pa}, \mathrm{O}_{2} / F \mathrm{I}, \mathrm{O}_{2}$ persisted (DSP/PL $\mathrm{r}_{\mathrm{s}}=0.59$, $\mathrm{p}=0.002$; DSP/ $\mathrm{SPH} \mathrm{r}_{\mathrm{s}}=0.59, \mathrm{p}=0.002 ; \mathrm{DSP} / \mathrm{urea}_{\mathrm{s}}=0.74, \mathrm{p}=0.0003 ; \mathrm{SP}-\mathrm{A} /$ $\mathrm{SPH}_{\mathrm{s}}=0.40, \mathrm{p}=0.04$; and SP-B/SPH $\mathrm{r}_{\mathrm{s}}=0.66, \mathrm{p}=0.0002$ ).

Table 2. - Phospholipid composition

\begin{tabular}{|c|c|c|c|c|}
\hline & $\begin{array}{c}\text { Normal BAL } \\
n=16\end{array}$ & $\begin{array}{c}\text { CS LAF } \\
\mathrm{n}=11\end{array}$ & $\begin{array}{c}\text { ALI LAF } \\
\mathrm{n}=15\end{array}$ & Comparison \\
\hline$\%$ DSP & $48.8 \pm 1.3$ & $34.2 \pm 5.1$ & $27.3 \pm 2.8$ & $e, f$ \\
\hline$\%$ PC & $68.1 \pm 1.5$ & $55.9 \pm 5.6$ & $57.5 \pm 2.9$ & $\mathrm{c}$ \\
\hline$\%$ PG & $8.3 \pm 0.3$ & $5.2 \pm 1.4$ & $9.3 \pm 2.4$ & \\
\hline$\%$ PI & $13.5 \pm 0.9$ & $11.5 \pm 2.4$ & $6.0 \pm 0.8$ & $\mathrm{a}, \mathrm{e}$ \\
\hline$\% \mathrm{PE}$ & $4.0 \pm 0.1$ & $4.1 \pm 0.9$ & $12.1 \pm 1.0$ & $\mathrm{~d}, \mathrm{e}$ \\
\hline$\%$ PS & $5.7 \pm 1.1$ & $16.3 \pm 3.3$ & $7.1 \pm 1.0$ & $\mathrm{~d}, \mathrm{f}$ \\
\hline \% LPC & $0.8 \pm 0.4$ & $4.4 \pm 1.8$ & $1.1 \pm 0.4$ & $\mathrm{a}$ \\
\hline$\% \mathrm{SPH}$ & $2.6 \pm 0.2$ & $6.7 \pm 1.0$ & $7.7 \pm 1.0$ & $e, f$ \\
\hline DSP/SPH & $20.5 \pm 2.3$ & $8.2 \pm 2.9$ & $5.2 \pm 0.9$ & $e, f$ \\
\hline PC/SPH & $28.7 \pm 2.6$ & $11.8 \pm 3.0$ & $9.4 \pm 1.2$ & $e, f$ \\
\hline PG/SPH & $3.5 \pm 0.3$ & $0.8 \pm 0.2$ & $1.6 \pm 0.6$ & $e, f$ \\
\hline PE/SPH & $1.7 \pm 0.1$ & $0.6 \pm 0.1$ & $2.1 \pm 0.3$ & $\mathrm{~d}$ \\
\hline PI/SPH & $5.7 \pm 0.5$ & $2.1 \pm 0.8$ & $1.1 \pm 0.2$ & $e, f$ \\
\hline PS/SPH & $1.4 \pm 0.4$ & $2.5 \pm 0.4$ & $1.0 \pm 0.1$ & $\mathrm{~d}$ \\
\hline LPC/SPH & $0.1 \pm 0.0$ & $0.6 \pm 0.4$ & $0.1 \pm 0.0$ & \\
\hline
\end{tabular}

Data are mean \pm SEM, and represent either a percentage of the total phospholipid or the ratio of phospholipid to sphingomyelin (SPH) in bronchoalveolar lavage (BAL) or lung aspirate fluid (LAF). CS: cardiac surgery; ALI: acute lung injury; DSP: disaturated phospholipid; PC: phosphatidylcholine; PE: phosphatidylethanolamine; PG: phosphatidyglycerol; PI: phosphatidylinositol; PS: phosphatidylserine; LPC: lysophosphatidylcholine. Differences between the groups were determined using analysis of variance and Tukeys highly significant difference test. ALI LAF versus CS LAF, a: $\mathrm{p}<0.05$, d: $\mathrm{p}<0.01$. ALI LAF versus normal BAL, b: $\mathrm{p}<0.05$, e: $\mathrm{p}<0.01$. CS LAF versus normal BAL, $\mathrm{c}: \mathrm{p}<0.05$, f: $\mathrm{p}<0.01$. 
Table 3. - Correlation $\left(r_{s}\right)$ of pulmonary surfactant with arterial oxygenation and respiratory medicine

\begin{tabular}{|c|c|c|c|c|c|}
\hline & $P \mathrm{a}, \mathrm{O}_{2} / F_{\mathrm{I}, \mathrm{O}_{2}}{ }^{\mathrm{a}}$ & $\begin{array}{c}E_{\mathrm{rs}, \mathrm{dyn}^{\mathrm{b}}} \\
\mathrm{cmH}_{2} \mathrm{O} \cdot \mathrm{L}^{-1}\end{array}$ & $\% E_{2} \mathrm{c}$ & $\begin{array}{c}E \Delta \mathrm{EELV}^{\mathrm{d}} \\
\mathrm{cmH}_{2} \mathrm{O} \cdot \mathrm{L}^{-1}\end{array}$ & p-value \\
\hline$\% \mathrm{DSP}$ & 0.75 & -0.18 & -0.76 & 0.70 & a 0.001 , bNS, c0.001, d0.04 \\
\hline$\% \mathrm{PC}$ & 0.33 & -0.14 & -0.37 & 0.32 & aNs, bNS, cNS, dNS \\
\hline$\% \mathrm{PE}$ & 0.48 & 0.18 & -0.40 & 0.45 & aNS, bNS, cNS, dNS \\
\hline$\% \mathrm{PG}$ & -0.23 & 0.07 & 0.08 & -0.25 & ans, bNS, cNS, dNS \\
\hline$\%$ PI & 0.52 & 0.44 & -0.14 & 0.55 & a0.046, bNS, cNS, d0.03 \\
\hline$\%$ PS & -0.29 & -0.26 & 0.50 & -0.56 & aNS, bNS, cNs, d0.03 \\
\hline$\%$ LPC & -0.52 & -0.26 & 0.32 & -0.53 & $\mathrm{a} 0.046, \mathrm{~b}_{\mathrm{NS}}, \mathrm{c}_{\mathrm{NS}}, \mathrm{d} 0.04$ \\
\hline$\% \mathrm{SPH}$ & -0.75 & -0.35 & 0.59 & -0.67 & $\mathrm{a} 0.001, \mathrm{~b} N \mathrm{NS}, \mathrm{c} 0.02, \mathrm{~d} 0.006$ \\
\hline DSP/SPH & 0.79 & 0.07 & -0.74 & 0.76 & a0.0005, bNS, c0.002, d 0.001 \\
\hline PC/SPH & 0.69 & 0.17 & -0.61 & 0.63 & a 0.004, bNS, c $0.02, \mathrm{~d} 0.01$ \\
\hline $\mathrm{PE} / \mathrm{SPH}$ & 0.80 & 0.21 & -0.63 & 0.64 & $\mathrm{a} 0.0003$, bNs, $0.01, \mathrm{~d} 0.01$ \\
\hline PG/SPH & 0.01 & 0.33 & 0.06 & 0.00 & ans, bNS, cNS, dNS \\
\hline $\mathrm{PI} / \mathrm{SPH}$ & 0.64 & 0.47 & -0.36 & 0.62 & $\mathrm{a} 0.01$, bNS, cNS, d 0.01 \\
\hline $\mathrm{PS} / \mathrm{SPH}$ & 0.28 & 0.10 & -0.16 & 0.06 & aNS, bNS, cNS, dNS \\
\hline LPC/SPH & -0.06 & -0.38 & 0.14 & -0.27 & aNs, bNS, cNS, dNS \\
\hline DSP/urea & 0.67 & 0.17 & -0.62 & 0.65 & $\mathrm{a} 0.009$, bNs, $0.01, \mathrm{~d} 0.02$ \\
\hline DSP/LPC & 0.87 & 0.13 & -0.71 & 0.87 & $\mathrm{a} 0.00002, \mathrm{~b} N \mathrm{~N}, \mathrm{c} 0.001, \mathrm{~d} 0.00002$ \\
\hline PC/LPC & 0.67 & 0.27 & -0.52 & 0.70 & $\mathrm{a} 0.009, \mathrm{~b}_{\mathrm{NS}}, \mathrm{c}_{\mathrm{NS}}, \mathrm{d} 0.005$ \\
\hline PG/PI & -0.42 & -0.09 & 0.22 & -0.48 & ans, bNS, cNS, dNS \\
\hline SP-A/SPH & 0.61 & 0.04 & -0.55 & 0.36 & a 0.01 , bNS, 0.03 , dNS \\
\hline SP-B/SPH & 0.71 & 0.09 & -0.49 & 0.48 & $\mathrm{a} 0.003, \mathrm{~b}_{\mathrm{NS}}, \mathrm{c}_{\mathrm{NS}}, \mathrm{d}_{\mathrm{NS}}$ \\
\hline SP-A/PL & 0.44 & 0.38 & -0.29 & 0.43 & aNS, bNS, cNS, dNS \\
\hline SP-B/PL & 0.38 & 0.34 & -0.18 & 0.37 & aNS, bNS, cNS, dNS \\
\hline
\end{tabular}

Correlation of normalized surfactant data with oxygenation or respiratory mechanics using Spearman rank order correlations. Initial surfactant data are expressed as a percentage of total phospholipid (PL; \%), and disaturated phospholipid (DSP)/urea represents DSP normalized to plasma and surfactant urea concentrations [14]. SP-A, SP-B: surfactant protein-A and -B. For further definitions see legend to table 2 .
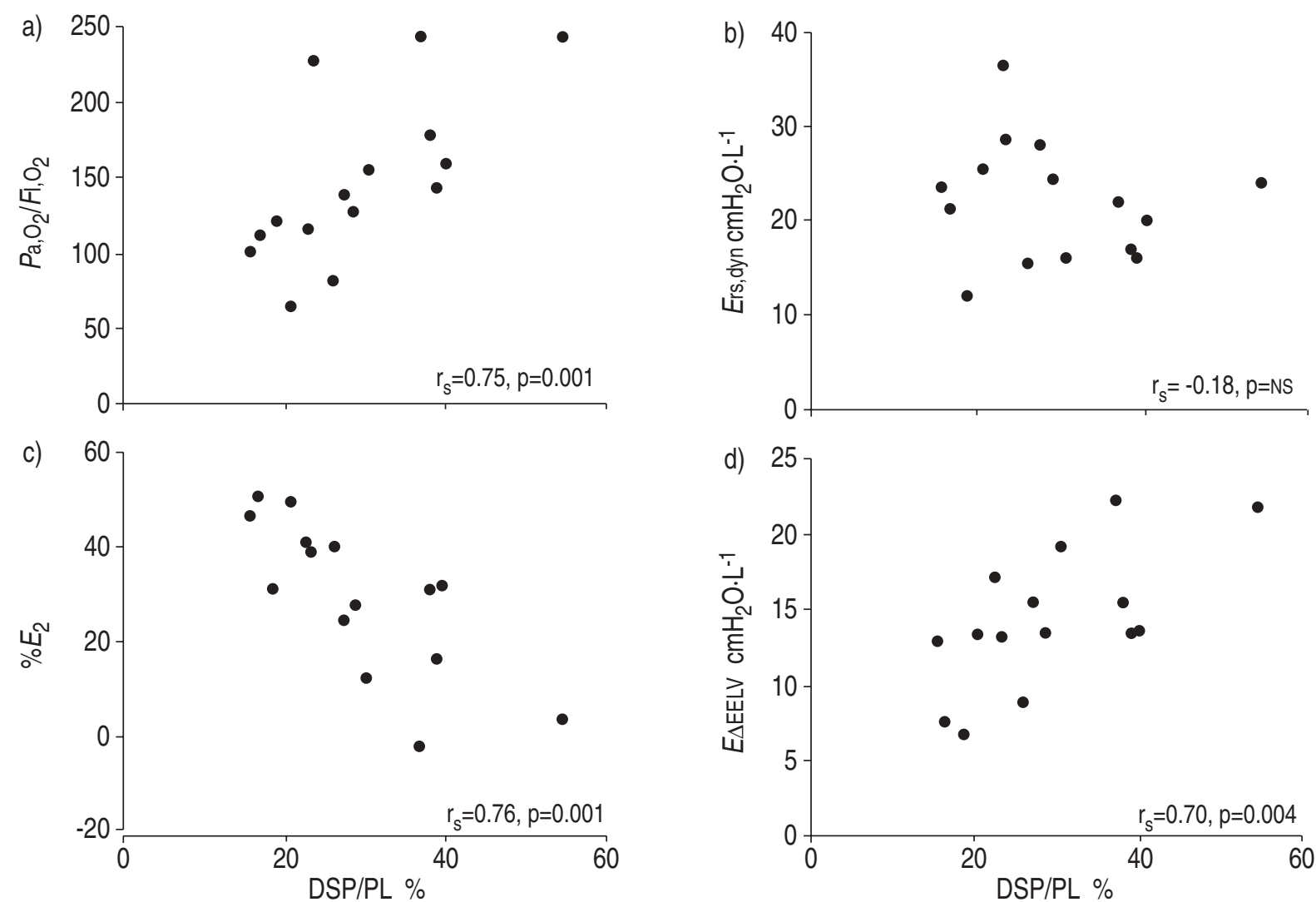

Fig. 1. - Relationship between the ratio of disaturated phospholipids (DSP) to total phospholipid (PL) and a) the quotient of arterial oxygen tension $\left(\mathrm{Pa}_{\mathrm{a}} \mathrm{O}_{2}\right)$ with the inspiratory oxygen fraction $\left(F \mathrm{I}, \mathrm{O}_{2}\right)$ concentration; b) the dynamic respiratory system elastance $(E \mathrm{rs}$,dyn $\left.) ; \mathrm{c}\right)$ lung inflation $\left(\% E_{2}\right)$; and d) the static elastance of the positive end-expiratory pressure-induced increase in the end-expiratory lung volume (EAEELV) in ventilated patients with acute lung injury. 

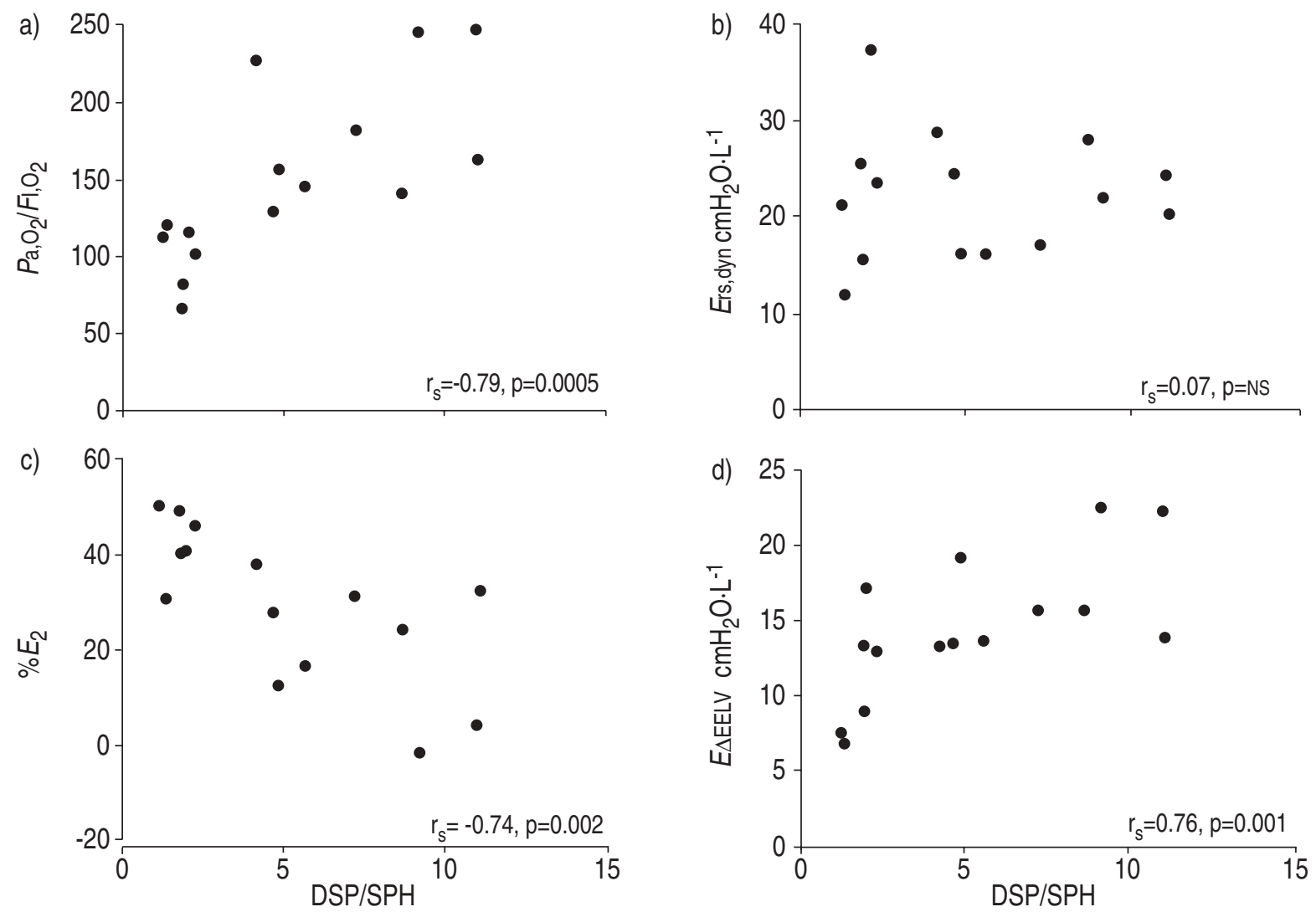

Fig. 2. - Relationship between the ratio of disaturated phospholipids (DSP) to sphingomyelin (SPH) and a) the quotient of arterial oxygen tension $\left(P \mathrm{a}, \mathrm{O}_{2}\right)$ with the inspiratory oxygen fraction $\left(\mathrm{F}_{\mathrm{I}} \mathrm{O}_{2}\right)$ concentration; b) the dynamic respiratory system elastance $\left.\left(E_{\mathrm{rs}, \mathrm{dyn}}\right) ; \mathrm{c}\right)$ lung inflation $\left(\% E_{2}\right)$; and d) the static elastance of the positive end-expiratory pressure-induced increase in the end-expiratory lung volume (EAEELV) in ventilated patients with acute lung injury.

When the CS cohort alone was analysed, similar relationships emerged, at least with regards to DSP (DSP/PL $\mathrm{r}_{\mathrm{s}}=0.57, \mathrm{p}=0.07 ; \mathrm{DSP} / \mathrm{SPH} \mathrm{r}_{\mathrm{s}}=0.60, \mathrm{p}=0.05 ;$ DSP/urea $\left.\mathrm{r}_{\mathrm{s}}=0.60, \mathrm{p}=0.05\right)$.

\section{Plasma surfactant proteins}

Plasma SP-A and -B were markedly elevated in the ALI patients compared with those in normal subjects and ventilated patients with no cardiorespiratory disease [9, 10], and were $759 \pm 70$ and $7174 \pm 1631 \mu \mathrm{g} \cdot \mathrm{mL}^{-1}$ respectively. The CS patients had SP-A and -B levels of $994 \pm 123$ and $4181 \pm 178 \mu \mathrm{g} \cdot \mathrm{mL}^{-1}$ respectively, similar to those found in the ALI patients. However, in both groups, the plasma levels of SP-A and -B were not related to their LAF surfactant levels, or to those of any of the phospholipids.

\section{Discussion}

Alveolar surfactant is essential for normal lung function, reducing surface tension and promoting alveolar stability. It has generally been accepted that impairment of surfactant function results in atelectasis, hypoxaemia, and decreased lung compliance, descriptive of the pathophysiology in ALI. We now report a correlation between oxygenation, respiratory mechanics, and pulmonary surfactant composition.

\section{Respiratory mechanics in ALI patients}

Respiratory system elastance, the inverse of compliance, is elevated in patients with ALI. Elastance may be elevated by an increase in the stiffness of the lung tissue itself, or by a reduction in the amount of lung being ventilated. In ALI, both factors appear to contribute. Computed tomography scans show collapse of dependent lung, while nondependent lung is more normally aerated, and GATTINONI and coworkers [15] have argued that this is due to a generalized increase in lung weight secondary to oedema and inflammation. Since global measures of elastance (Ers,dyn in the current study) are strongly influenced by aerated lung size, the failure to find a relationship with the pulmonary surfactant state was not unexpected. How- ever, if surface tension normally contributes $2 / 3$ of lung elastance [8], surfactant abnormalities must play a role through both abnormal elastance of ventilated lung, and through promotion of alveolar collapse. It is noteworthy that we did find strong relationships with $\% E_{2}$ and $E \Delta \mathrm{EELV}$; variables that would be expected to better reflect the non-uniform respiratory mechanics present in our pa-tients. Finally, the presence of type III procollagen peptide in BAL fluid three days after the onset of ARDS [16], and in pulmonary oedema fluid on day 1 [17], suggests that fibrosing alveolitis will also contribute to early increases in respiratory elastance.

In addition to $\% E_{2}$, we calculated the EAEELV in an attempt to further quantitate the heterogeneous mechanics 
present in ALI. In healthy lung, the EAEELV would be expected to be high since it would contain minimal collapsed lung, whereas in severe ALI where there is a greater mass of lung available for recruitment, a relatively lower elastance would consequently be expected. A large mass of collapsed lung, and consequently a small mass of ventilated lung, would generally be associated with a high $\% E_{2}$. Of course, this would be influenced by the applied PEEP and the delivered $V \mathrm{~T}$, and must reflect the pattern of ventilation used in the current study. However, while in-creased levels of PEEP generally recruited collapsed lung, there was usually an increase in $\% E_{2}$ suggesting that re-cruitment and overinflation occurred concurrently. Given the small range of applied PEEP $\left(5-10 \mathrm{cmH}_{2} \mathrm{O}\right)$ and $V \mathrm{~T}(8-10$ $\left.\mathrm{mL} \cdot \mathrm{kg}^{-1}\right)$, we feel that the conditions under which $\% E_{2}$ was measured are similar, thus allowing comparison of patients.

\section{Surfactant sampling}

Pulmonary surfactant may be sampled by whole lung lavage, BAL, tracheal aspiration or aspiration of lower lung fluid. A temporary aggravation of hypoxaemia precludes BAL in the most severely hypoxaemic patients, and nondiagnostic sampling of BAL fluid in sedated pati-ents, posed local ethical problems. Consequently, we sampled LAF from ALI and CS patients, and BAL from healthy, awake subjects.

We adopted a technique similar to that of MAтTHAY and coworkers [17, 18], who have sampled pulmonary oedema fluid by blindly wedging a suction catheter and aspirating lung fluid from patients with ALI and HPE. The presence of a linear relationship between DSP and SP-A and -B in our LAF (data not shown) strongly suggests that this method of sampling reflects surfactant composition. BERNHARD et al. [19] also found that conducting airway fluid reflected alveolar surfactant composition. Numerous other investigators have used aspirated fluid to examine surfactant composition in neonates [20-22], children [23] and adults [24] with respiratory failure, and noted that the relative surfactant composition is similar to that obtained from BAL. For example, LeVINE et al. [23] reported a PC/ $\mathrm{SPH}$ value of $41.8 \pm 10.6$ in their control fluid, little different from our BAL data $(28.7 \pm 2.6)$ and some four times greater than that in our ALI LAF $(9.4 \pm 1.2)$, suggesting that sampling differences do not explain why our ALI data differ from normal.

A further inherent problem, regardless of the method of harvesting, is determining whether all the material is truly associated with surfactant. Possibly included is material from the airways and extraneous material from the alveolar compartment. Also, it is impossible to determine the absolute amounts of surfactant present in the alveolus on the basis of partial lung BAL. Recovery is variably affected by numerous factors including the surface area lavaged, the amount of saline recovered, the duration over which the saline was instilled, and the efficacy of the washing. Despite having performed 200 BAL on normal subjects over the last few years, we have found [11] that clearance of saline varies enormously even between the normal subjects. However, since we routinely find direct relationships between the concentration of SP-A, DSP and cholesterol in the BAL fluid [11], we suggest that the percentage of components of surfactant recovered from the lavages is relatively consistent $[11,25]$. Therefore, we have expressed our results as percentages of total phospholipid, or in relation to DSP, the hallmark of surfactant.

Sphingomyelin is the most commonly used denominator in surfactant research, particularly in the assessment of foetal lung maturity [26]. However, since SPH may not be a component of surfactant, possibly originating from damaged membranes [27], normalizing the data to SPH may only secondarily and fortuitously reflect total surfactant status. We have therefore also normalized our data to total PL and the nonsurfactant component, urea. Data normalized to PL may better reflect the balance of type II cell production and metabolism of surfactant, while urea is a freely diffusible molecule with the ratio of alveolar-toplasma urea used to compensate for dilutional differences between specimens [14]. It is noteworthy that the DSP data remained significantly correlated with lung function independent of which normalizing method was used. Furthermore, when combined with the CS group these correlations were maintained, indicating robust data.

\section{Surfactant composition and lung function in patients with} ALI

The disaturated phospholipids are generally regarded as the principal functional components of surfactant, whereas SP-A and -B are essential for surface absorption and homeostasis. Importantly, we found that the ratios DSP/ SPH, DSP/PL, DSP/urea and DSP/LPC were related directly to blood oxygenation and EAEELV, and indirectly to $\% E_{2}$ in our ALI patients.

Since the SPH/PL ratio was related indirectly to oxygenation and $E \Delta \mathrm{EELV}$ and directly to $\% E_{2}$, these relationships cannot be explained by changes in SPH or PL alone. For example, with increasing blood oxygenation the direct relationship with DSP/SPH could arise through either relative increases in DSP, or decreases in SPH. Similarly, with increasing blood oxygenation the direct relationship with DSP/PL could arise through either relative increases in DSP, or decreases in PL. However, the relative decreases in PL or SPH alone are incompatible with the inverse relationship between SPH/PL and blood oxygenation. The critical inverse relationship between SPH/PL and blood oxygenation indicates that, in this example, better oxygenation is associated with proportionately higher levels of DSP, than decreases in either PL or SPH, a finding further supported by normalizing DSP to urea. By extension, the same rationale holds true for the other relationships described.

Phospholipase $\mathrm{A}_{2}$ degrades PC, and generates LPC as its first product. Phospholipase $\mathrm{A}_{2}$ activity has been associated with impaired lung function [28], and may be induced by an increased load of reactive oxygen species. Lysophosphatidylcholine is a detergent-like molecule which directly interferes with the surface properties of surfactant [29], and is also toxic to the epithelium [30]. The finding that the DSP/LPC and PC/LPC ratios directly correlated with $P \mathrm{a}, \mathrm{O}_{2} / F \mathrm{I}, \mathrm{O}_{2}$ and $E \Delta \mathrm{EELV}$, and indirectly with $\% E_{2}$ in our ALI patients is consistent with increased catabolism of PC and a concomitant drop in the PC/LPC ratio, leading to a deterioration in respiratory function. 
PIson et al. [7] have reported that ALI is associated with reduced SP-A levels in BAL fluid, and, GREGoRY et al. [2] have reported that SP-B is also reduced. However, GuNTHER et al. [6] have recently disputed this. Whatever the case, both groups note that whereas ARDS is associated with decreased PL, the SP-A/PL ratio in their patients was no different. Possibly consistent with this, we found that SP$\mathrm{A} / \mathrm{PL}$ and SP-B/PL were not related to lung function.

\section{Surfactant proteins in plasma}

We have previously reported that blood levels of SP-A and SP-B are elevated in patients with ALI, and correlate with the severity of the respiratory dysfunction $[9,10]$. It seems likely that this phenomenon reflects an increase in alveolocapillary permeability rather than an increase in their lung content, as there was no relationship between the plasma levels of these proteins and surfactant composition. If the increased plasma levels of SP-A and -B merely reflected increased levels of the proteins in the alveolus, such relationships may have been anticipated. Moreover, in agreement with PISON et al. [7] and GREGORY et al. [2], our normalized surfactant SP-A and -B levels were reduced in ALI, in contrast with the plasma levels. We conclude that elevated plasma SP-A and -B reflect changes in lung permeability rather than changes in alveolar levels. Surprisingly, plasma SP-A and -B were also elevated in the $\mathrm{CS}$ group.

\section{Cardiac surgery patients}

Although we predicted that CS surfactant would act as a suitable control, its composition was clearly aberrant and indeed not dissimilar to that from our ALI patients. Moreover, whereas the DSP/PL, DSP/SPH, DSP/urea, SP$\mathrm{A} / \mathrm{SPH}$ and SP-B/SPH ratios were all related to oxygenation in the ALI group, this was also true when the CS cohort was added. When the CS cohort alone was analysed, similar relationships emerged, at least with regard to DSP. While the finding that CS surfactant is abnormal was unexpected, it is consistent with the elevated plasma levels of SP-A and SP-B found in these patients, and suggests coexistent lung injury. Consistent with this, we have previously reported elevated blood levels of SPA [9] and SP-B [10], and others have found elevated protein [31] and oxidized glutathione [32] in BAL fluid from patients with HPE. Furthermore, PETERSON et al. [33] found a doubling of total protein in epithelial lining fluid when the left atrial pressure was raised $19 \mathrm{cmH}_{2} \mathrm{O}$ in sheep, and the alveolar-to-plasma protein ratio was almost identical to that reported from HPE patients [18]. Of particular note, and consistent with the current study where 7 of the $11 \mathrm{CS}$ patients required cardiac valve replacement for chronic and severe heart failure, $\mathrm{N}_{\mathrm{AKOS}}$ et al. [31] found that ARDS and HPE patients had similar surfactant changes. Although we did not measure extravascular lung water in these patients, it is almost certain they also had pulmonary oedema. However, many uncertainties exist, and these issues require further investigation.

In summary, we have described the correlation of oxygenation and lung mechanics with the surfactant status of acute lung injury and cardiac surgery patients. Surfac- tant composition correlated with lung function. Consistent with our previous studies $[9,10]$, plasma surfactant protein-A and -B was elevated in our acute lung injury patients. Plasma surfactant protein-A and -B was also elevated in our cardiac surgery patients. Although initially surprising, our present results are consistent with the work of others [31-33], and reflect concurrent lung dysfunction and an increase in alveolocapillary permeability in cardiac surgery patients. While it has been convenient to partition pulmonary oedema as due to either a hydrostatic or permeability origin, accumulating data $[9,10,31-33]$ suggests that this is only a notional classification, and that there is usually a variable component to both. Finally, we conclude that elevated plasma surfactant protein-A and -B reflect changes in lung permeability rather than absolute changes in alveolar levels.

Acknowledgement: The assistance of the Critical Care Unit consultants, registrars and nursing staff are gratefully acknowledged.

\section{References}

1. Ashbaugh DG, Bigelow DB, Petty TL, Levine BE. Acute respiratory distress in adults. Lancet 1967; 2: 319-323.

2. Gregory TJ, Longmore WJ, Moxley MA, et al. Surfactant composition and biophysical activity in acute respiratory distress syndrome. J Clin Invest 1991; 88: 1976-1981.

3. Pison U, Seeger W, Buchhorn R, et al. Surfactant abnormalities in patients with respiratory failure after multiple trauma. Am Rev Respir Dis 1989; 140: 1033-1039.

4. Pison U, Obertake U, Brand M, et al. Altered pulmonary surfactant in uncomplicated and septicemia-complicated courses of acute respiratory failure. J Trauma 1990; 30: $19-26$.

5. Hallman M, Spragg R, Harrell JH, Moser KM, Gluck L. Evidence of lung surfactant abnormality in respiratory failure - study of bronchoalveolar lavage phospholipids, surface activity, phospholipase activity, and plasma myoinositol. J Clin Invest 1982; 70: 673-683.

6. Gunther A, Siebert C, Schmidt R, et al. Surfactant alterations in severe pneumonia, acute respiratory distress syndrome, and cardiogenic lung edema. Am J Respir Crit Care Med 1996; 153: 176-184.

7. Pison U, Obertacke U, Seeger W, Hawgood S. Surfactant protein A (SP-A) is decreased in acute parenchymal lung injury associated with polytrauma. Eur J Clin Invest 1992; 22: 712-718.

8. Radford EP. Recent studies of mechanical properties of mammalian lungs. In: Remington JW, ed. Tissue Elasticity. Washington, DC, Am Physiol Soc, 1957; pp. 177190.

9. Doyle IR, Nicholas TE, Bersten AD. Serum surfactant protein-A levels in patients with acute cardiogenic pulmonary edema and adult respiratory distress syndrome. Am J Respir Crit Care Med 1995; 152: 307-317.

10. Doyle IR, Bersten AD, Nicholas TE. Surfactant proteinsA \& -B are elevated in plasma of patients with acute respiratory failure. Am J Respir Crit Care Med 1997; 156: 1217-1229.

11. Doyle IR, Jones ME, Orgeig S, et al. The ratio of surfactant protein A (SP-A), cholesterol and disaturated phospholipid in human surfactant varies with level of fitness and exercise. Am J Respir Crit Care Med 1994; 149: $1619-1627$. 
12. Kano S, Lanteri CJ, Duncan AW, Sly PD. Influence of nonlinearities on estimates of respiratory mechanics using multilinear regression analysis. J Appl Physiol 1994; 77: 1185-1197.

13. Pison U, Gono E, Joka T, Obertacke U, Obladen M. High-performance liquid chromatography of adult human bronchoalveolar lavage: assay for phospholipid lung profile. J Chromatogr 1986; 377: 79-89.

14. Holter JF, Weiland JE, Pacht ER, Gadek JE, Davis WB. Protein permeability in the adult respiratory distress syndrome: loss of size selectivity of the alveolar epithelium. J Clin Invest 1986; 78: 1513-1522.

15. Pelosi P, D'Andrea L, Vitale G, Pesenti A, Gattinoni L. Vertical gradient of regional lung inflation in adult respiratory distress syndrome. Am J Respir Crit Care Med 1994; 149: 8-13.

16. Clark JG, Milberg JA, Steinberg KP, Hudson LD. Type III procollagen peptide in the adult respiratory distress syndrome. Association of increased peptide levels in bronchoalveolar lavage fluid with increased risk for death. Ann Intern Med 1995; 122: 17-23.

17. Chestnutt AN, Matthay MA, Tibayan FA, Clark JG. Early detection of type III procollagen peptide is present in acute lung injury: pathogenetic and prognostic significance. Am J Respir Crit Care Med 1997; 156: 840-845.

18. Pittet JF, Mackersie RC, Martin TR, Matthay MA. Biological markers of acute lung injury: prognostic and pathogenetic significance. Am J Respir Crit Care Med 1997; 155: 1187-1205.

19. Bernhard W, Haagsman HP, Tschernig T, et al. Conductive airway surfactant: surface-tension function, biochemical composition, and possible alveolar origin. Am J Respir Cell Mol Biol 1997; 117: 41-50.

20. Wilkinson A, Jenkins PA, Jeffrey JA. Two trials of dry artificial surfactant: early effects and later outcome in babies with surfactant deficiency. Lancet 1985; 2: $287-$ 291.

21. Hallman M, Merritt TA, Pohjavuori M, Gluck L. Effect of surfactant substitution on lung effluent phospholipids in respiratory distress syndrome: evaluation of surfactant phospholipid turnover, pool size, and the relationship to severity of respiratory failure. Pediatr Res 1986; 20: $1228-1235$.

22. Gerdes J, Whitsett J, Long W. Elastase activity and sur- factant protein concentration in tracheal aspirates from neonates receiving synthetic surfactant. J Pediatr 1992; 120: S34-S39.

23. LeVine AM, Lotze A, Stanley S, et al. Surfactant content in children with inflammatory lung disease. Crit Care Med 1996; 24: 1062-1067.

24. Jacobson W, Park GR, Saich T, Holcroft J. Surfactant and adult respiratory distress syndrome. Br J Anaesth 1993; 70: 522-526.

25. Doyle IR, Davidson KG, Payne K, Barr HA, Pfitzner J, Nicholas TE. Quantity and structure of surfactant proteins vary in patients with alveolar proteinosis. Am J Respir Crit Care Med 1998; 157: 658-664.

26. Gluck LM, Kulovich MV, Borer RC, Brenner PH, Anderson GG, Spellacy WN. The interpretation and significance of the lecithin/sphingomyelin ratio in amniotic fluid. Am J Obstet Gynecol 1974; 120: 142-155.

27. Neumann MA, McMurchie EJ, Gibson RA. A comparison of lung lamellar body phospholipids from premature and term infants: is sphingomyelin a contaminant of surfactant? Pediatr Pulmonol 1990; 9: 162-165.

28. Vada P. Elevated plasma phospholipase $\mathrm{A}_{2}$ levels: correlation with the hemodynamic and pulmonary changes in Gram-negative septic shock. J Lab Clin Med 1984; 104: 873-881.

29. Holm BA, Keicher L, Liu M, Sokolowski J, Enhorning G. Inhibition of pulmonary surfactant by phospholipases. $J$ Appl Physiol 1991; 71: 317-321.

30. Niewwoehner DE, Rice K. Injurious effects of lysophosphatidylcholine on barrier effects of alveolar epithelium. J Appl Physiol 1987; 63: 1979-1986.

31. Nakos G, Pneumatikos J, Tsangaris I, Tellis C, Lekka M. Proteins and phospholipids in BAL from patients with hydrostatic pulmonary edema. Am J Respir Crit Care Med 1997; 155: 945-951.

32. Bunnell E, Pacht ER. Oxidized glutathione is increased in the alveolar fluid of patients with the adult respiratory distress syndrome. Am Rev Respir Dis 1993; 148: 11741178.

33. Peterson BT, Idell S, Macarthur C, Gray LD, Cohen AB. A modified bronchoalveolar lavage procedure that allows measurement of lung epithelial lining fluid volume. Am Rev Respir Dis 1990; 141: 314-320. 